\title{
Serotonin reuptake inhibitors and post- gastrostomy bleeding: reevaluating the link
}

This article was published in the following Dove Press journal:

Therapeutics and Clinical Risk Management

27 August 2015

Number of times this article has been viewed

\section{Harish Patel \\ Vinaya Gaduputi \\ Sailaja Sakam \\ Kishore Kumar \\ Chukwunonso Chime \\ Bhavna Balar}

Department of Medicine, Bronx Lebanon Hospital Center, Bronx, NY, USA
Correspondence: Vinaya Gaduputi Department of Medicine, Bronx Lebanon Hospital Center, 1650 Selwyn Avenue, Suite \#I0C, Bronx, NY I0457, USA

$\mathrm{Tel}+17189601234$

Email vgaduput@bronxleb.org
Introduction: Serotonin reuptake inhibitors (SRIs) are one of the most commonly prescribed classes of medications with a relatively safe side-effect profile. However, SRIs are being increasingly reported to be associated with bleeding complications in patients undergoing invasive procedures resulting from inhibition of serotonin reuptake by platelets and impaired platelet aggregation. The aim of our study was to determine whether there is an increased risk of postpercutaneous endoscopic gastrostomy (PEG) bleeding in patients exposed to SRIs after controlling for other mediations known to increase the risk of bleeding and major comorbidities.

Methods: This was a single-center cohort study that included who underwent PEG tube placement by standard pull-guidewire technique from July 2006 to June 2014. Patients were categorized into groups based on the medications (SRIs, aspirin, non-steroidal anti-inflammatory drugs, and anticoagulants) administered during the index hospitalization. The incidence of postPEG bleeding was noted in two distinct post-procedure periods: within 48 hours, and between 48 hours and 14 days.

Results: A total of 637 PEG tube placements were done on 570 patients during the study period. There were 107 patients $(18.8 \%)$ with major bleeding within 48 hours of PEG and 79 patients $(13.9 \%)$ with major bleeding between 48 hours and 14 days. There was no significant increase in the post-PEG bleeding in patients taking a combination of an SRI along with aspirin or non-steroidal anti-inflammatory drugs. Patients on subcutaneous heparin for prophylaxis against thromboembolic events were more likely to have oozing at the PEG site requiring blood transfusion.

Conclusion: We did not notice an increase in post-PEG bleeding in patients on SRIs. However, in view of the limitation that our study is retrospective and that there are no known significant side effects of withdrawal of SRIs for a short duration, withholding SRIs could be a safe clinical option in patients undergoing PEG tube placement.

Keywords: PEG bleeding, gastrostomy bleeding, PEG, gastrostomy, SSRI bleeding, SRI bleeding

\section{Introduction}

Serotonin reuptake inhibitors (SRIs) are one of the most commonly prescribed classes of medications. The relatively safe side-effect profile and their versatility in therapeutic effect for a multitude of psychiatric disorders such as depression, anxiety disorders, panic disorders, premature ejaculation, eating disorders, obsessive-compulsive disorder, and even chronic pain have made them a first choice agent for many clinicians. However, with exponentially widened usage within the last decade, ${ }^{1}$ deleterious effects of SRIs are being increasingly reported, particularly in special situations such as surgery and unintentional trauma. SRIs have been associated with bleeding complications that manifest with impaired platelet aggregation, ${ }^{2}$ prolonged bleeding time, ${ }^{3}$ and spontaneous mucosal bleeds. Even though the exact pathophysiology of 
SRI-induced platelet dysfunction has not been elucidated, the most widely accepted theory is that they inhibit serotonin reuptake by platelets. ${ }^{4,5}$ Platelets depend on absorption of serotonin from blood stream for their serotonin stores, as they lack intrinsic apparatus for its denovo synthesis. Serotonin is known to be important in the formation of platelet plug along with other co-factors such as adenosine diphosphate and prothrombin. SRIs thereby reduce platelet aggregation secondary to depletion of platelets' serotonin stores. ${ }^{4}$ It is therefore imperative that clinicians attempting invasive procedures on patients taking SRIs be aware of possible risk of bleeding diathesis. This should of concern for the physician placing a percutaneous endoscopic gastrostomy (PEG) tube. Gastrointestinal bleeding is a rare complication of PEG tube placement, the risk of which is increased with concomitant administration of antiplatelet agents such as aspirin and clopidogrel. ${ }^{6}$ As per consensus, aspirin need not be stopped in patients at a higher risk for thromboembolic events, ${ }^{7}$ while undergoing PEG tube placement. There is also evidence that the use of SRIs increases the risk of bleeding following PEG placement. ${ }^{8}$ While no recommendations exist about stopping SRIs in patients undergoing PEG placement, it is has been suggested that stopping SRIs 24 hours before the procedure might be associated with less complications.

The aim of our study was to determine whether there is an increased risk of post-procedural bleeding in patients exposed to SRIs, aspirin, clopidogrel, therapeutic anti-coagulation, non-steroidal anti-inflammatory drugs (NSAIDs), and heparin for thromboembolic prophylaxis, before the procedure.

We also examined whether comorbidities such as cirrhosis, major cardiovascular disease, chronic kidney disease, cerebrovascular disease, HIV, and malignancy increased the risk of bleeding after PEG tube placement.

\section{Methods}

\section{Study population and data sources}

We conducted a retrospective, single-center cohort study that included patients at Bronx Lebanon Hospital Center who underwent PEG tube placement by standard pull-guidewire technique from July 2006 to June 2014. The institutional review board at Bronx Lebanon Hospital approved this study. Patients included in the study were identified using an electronic reporting system at the division of Gastroenterology. The electronic medical records for these patients were reviewed for admitting history, physical examination findings, progress notes, discharge summaries, medication $\operatorname{logs}$, laboratory values, endoscopy reports, operative notes, and transfusion records.

\section{Inclusion and exclusion criteria}

We included all adult patients who underwent endoscopic placement of gastrostomy tube by gastroenterologists at our hospital between July 2006 and June 2014. All the procedures involved the placement of a 20F (20 French) gastrostomy tube. Among patients who underwent multiple procedures, only the first PEG procedure was taken into account for the study. All the PEG procedures were performed by an experienced gastroenterology attending while being assisted by a fellow. All patients were under monitored anesthesia care with sedation being achieved with a combination of Propofol and Midazolam.

\section{Patient data observed}

We obtained data on the following patient characteristics assessed at hospital discharge: age, sex, race comorbid conditions (cirrhosis, HIV, hypertension, cerebrovascular disease, cardiovascular disease, and malignancy) and indications for PEG tube placement. Medications administered at the time of undergoing PEG tube placement including SRIs, antiplatelet agents, NSAIDs, and anticoagulants were noted. Laboratory values (hemoglobin, platelets, creatinine, albumin, and international normalized ratio [INR]) at the time of the procedure were retrieved. Most of the patient had a repeat complete blood count done within 48 hours of the procedure. All the patients were followed by a gastroenterology fellow within 24 hours of the procedure. The post-procedure notes were reviewed for the PEG site bleeding and management of the same. The records of blood transfusion in the electronic medical records, where applicable, were also retrieved.

\section{Definitions used in the study Definition of index medications}

1. SRIs (serotonin reuptake inhibitors).

a. Selective serotonin reuptake inhibitors included citalopram, escitalopram, fluoxetine, fluvoxamine, paroxetine, and sertraline.

b. Selective serotonin and norepinephrine reuptake inhibitors included venlafaxine and duloxetine hydrochloride.

2. Prophylactic anticoagulants included prophylactic subcutaneous (SQ) heparin.

3. Therapeutic anticoagulants included therapeutic dose of intravenous heparin or low molecular weight and warfarin.

4. NSAIDs included non-salicylate, non-COX-2 selective NSAIDs such as ibuprofen and naproxen. 
5. Aspirin (any dose) and clopidogrel used for primary or secondary prophylaxis.

Patients were categorized into groups based on the medications (SRIs, aspirin, NSAIDs, and anticoagulants in therapeutic or prophylactic dose) administered during the index hospitalization.

\section{Definition of exposure to the index medication}

Exposure was considered as positive if the index drug (aspirin, NSAIDs, SRIs, and SQ heparin) was dispensed to the patient within 48 hours before or 48 hours after PEG tube placement. The patients who were on the therapeutic anticoagulation were bridged appropriately during the procedure.

\section{Definition of outcome}

Post-PEG tube placement bleeding was defined by one of the following:

1. Overt upper gastrointestinal bleed including hematemesis or melena, with or without a need for transfusion.

2. Decrease in hemoglobin level of $\geq 2 \mathrm{~g} / \mathrm{dL}$ compared with value just before the PEG tube placement.

3. Local PEG site bleeding or oozing that required blood transfusion.

\section{Interval considered for measuring the outcome}

The study outcomes were noted in two groups based on the duration of the post-PEG bleeding episode.

1. Post-PEG bleeding "within 48 hours".

2. Post-PEG bleeding "between 48 hours and 14 days".

\section{Statistical analysis}

Categorical and continuous demographics and clinical characteristics (SRIs, aspirin, clopidogrel, NSAIDs, and anticoagulation use before PEG, platelet counts, and hemoglobin concentration) were individually compared between patients who had a major bleed as per definition and those who did not bleed after PEG placement by using the Student's $t$-test and $\chi^{2}$ test. Potential confounders such as liver cirrhosis were adjusted before comparing the bleeders and non-bleeders. All reported $P$-values were two-sided and a $P$-value of 0.05 was considered as significant. All statistical analyses were performed by using SPSS version 19.

\section{Results}

\section{Baseline demographics}

A total of 637 PEG tube placements were done on 570 patients during the study period. The study population had a mean age of $68.8( \pm 15.57)$ years (range $21-104$ years).
It consisted of $47.7 \%(n=272)$ of males and $52.3 \%(n=298)$ of females.

The study population included African Americans $(n=275,48.2 \%)$, Hispanics $(n=151,26.5 \%)$, Caucasians $(n=32,5.8 \%)$, and others $(n=112,19.5 \%)$. The indications of PEG included dementia with failure to thrive ( $n=201,35.3 \%)$, dysphagia $(n=115,20.2 \%)$, cerebrovascular accident $(n=169$, $26.7 \%)$, malignancy, and others $(n=85,14 \%)$.

\section{Demographic variables distribution and post-PEG tube bleeding}

There were total of 107 patients (18.8\%) with evidence of bleeding that met the criteria of major bleeding within 48 hours after PEG tube placement. Of these, 70 patients $(12.3 \%)$ had a drop in the hemoglobin by at least $2 \mathrm{~g} / \mathrm{dL}$ and 33 patients $(5.8 \%)$ required blood transfusion after oozing was noted at the PEG site, while 9 patients (1.6\%) manifested upper gastrointestinal bleeding in the form of hematemesis or melena. There were 79 patients $(13.9 \%)$ with major bleeding between 48 hours and 14 days. Of these, 69 patients $(12.1 \%)$ had a drop in the hemoglobin by at least $2 \mathrm{~g} / \mathrm{dL}, 13$ patients $(2.3 \%)$ required blood transfusion after oozing was noted at the PEG site, and 2 patients $(0.4 \%)$ had overt gastrointestinal bleeding. The incidence of major gastrointestinal bleeding has been tabulated in Table 1.

The distribution of baseline demographic variables between the two groups of patients (those who bled within 48 hours of PEG placement and those who bled between 48 hours and 14 days after PEG tube placement) is shown in Table 2. The patients with liver cirrhosis were more likely to bleed in both these groups. Those who had bleeding within 48 hours of PEG placement were more likely to be older and had a higher baseline hemoglobin level as compared with those who did not have bleeding within 48 hours.

\section{Index medications and post-PEG tube bleeding}

A total of 67 (11.8\%) PEG tubes were placed in patients while on SRIs, 221 (38.8\%) PEG tubes were placed in patients while on aspirin, and $16(2.8 \%)$ PEG tubes were placed in patients while on clopidogrel. Clopidogrel was stopped for duration of more than 5 days in 15 patients and restarted after 48 hours of PEG placement. There were total of 28 patients $(5 \%)$ who were on therapeutic anticoagulation of whom 23 were on intravenous heparin while 5 patients were on low molecular weight heparin (LMWH). Therapeutic anticoagulants were held for 6-12 hours before the procedure and initiated within 12-24 hours after the procedure. There were 
Table I Incidence of major gastrointestinal bleeding post-PEG tube placement

\begin{tabular}{lll}
\hline Type of bleeding event & \multicolumn{2}{c}{ Duration: PEG insertion to bleeding event } \\
\cline { 2 - 3 } & Less than $\mathbf{4 8}$ hours & Between $\mathbf{4 8}$ hours and I4 days \\
\hline Patients with post-PEG bleed & $107(18.8 \%)$ & $79(13.9 \%)$ \\
Decrease in hemoglobin of more than $2 \mathrm{~g} / \mathrm{dL}$ & $70(12.3 \%)$ & $69(12.1 \%)$ \\
PEG site oozing requiring blood transfusion & $33(5.8 \%)$ & $13(2.3 \%)$ \\
Hematemesis/melena & $9(1.6 \%)$ & $2(0.4 \%)$ \\
\hline
\end{tabular}

Abbreviation: PEG, percutaneous endoscopic gastrostomy.

294 (44\%) patients on the prophylactic anticoagulation with SQ heparin at the time of PEG tube placement. Twenty-six patients $(4.6 \%)$ were on NSAIDs. There was no significant increase in the post-PEG tube bleeding in patients taking a combination of an SRI along with aspirin or NSAIDs. The correlation of the index medication with post-PEG tube bleeding was analyzed after controlling for potential cofounders like liver cirrhosis. Bleeding rates with different index medications are shown in Table 3.

The distribution of presentations for gastrointestinal bleeding was analyzed in patients who were on SRIs. There was no statistical difference in these presentations in the two study groups, except for the decrease in hemoglobin by $\geq 2 \mathrm{~g} / \mathrm{dL}$. On reviewing the presentations for therapeutic intravenous heparin, LMWH, and prophylactic SQ heparin, it was noted that those on SQ heparin for prophylaxis against thromboembolic events were more likely to have oozing at the PEG site requiring blood transfusion. The incidences of bleeding with different types of anticoagulation and SRIs have been tabulated in Table 4 .

Patients on SRIs were found not to have a significantly increased risk of bleeding on multivariate analysis, after controlling for confounding factors like the use of unfractioned heparin in thrombophylactic dose, platelet count, INR, and liver cirrhosis (Table 5).

\section{Discussion}

As per American Society for Gastrointestinal Endoscopy classification, PEG tube placement is considered as a highrisk procedure with up to $2.5 \%$ risk of bleeding. ${ }^{9,10}$ The definition of the post-PEG bleeding varies among different studies. In our study, we noticed relatively higher rate of postPEG bleeding with the drop in the hemoglobin of $\geq 2 \mathrm{~g} / \mathrm{dL}$ accounting for the majority of it. The parental hydration, central venous access, and longer lengths of stay with repeated phlebotomies can have also contributed to interval decrease

Table 2 Distribution of baseline demographic characteristics, medical comorbidities, and laboratory parameters in the two study groups

\begin{tabular}{|c|c|c|c|c|c|c|}
\hline \multirow{3}{*}{$\begin{array}{l}\text { Baseline patient } \\
\text { characteristics } \\
\text { Demographic }\end{array}$} & \multicolumn{6}{|c|}{ Bleeding interval } \\
\hline & \multicolumn{2}{|c|}{$<48$ hours after PEG $(107)$} & \multirow[t]{2}{*}{$P$-value } & \multicolumn{2}{|c|}{$\begin{array}{l}\text { Between } 48 \text { hours and } \\
\text { I } 4 \text { days ( } 79)\end{array}$} & \multirow[t]{2}{*}{$P$-value } \\
\hline & No bleeding & Bleeding & & No bleeding & Bleeding & \\
\hline Age $( \pm S D)$ & $68 \pm 16$ & $72 \pm 16$ & 0.04 & $69 \pm 16$ & $69 \pm 16$ & 0.9 \\
\hline Sex & & & 0.54 & & & 0.59 \\
\hline Male (\%) & $218(38.2 \%)$ & $54(9.5 \%)$ & & $242(42.5 \%)$ & $30(5.3 \%)$ & \\
\hline Female (\%) & $244(42.8 \%)$ & $53(9.3 \%)$ & & $248(43.5 \%)$ & $49(8.6 \%)$ & \\
\hline \multicolumn{7}{|l|}{ Comorbidity } \\
\hline CVA (\%) & 134 (23.5\%) & $340(59.6 \%)$ & 0.58 & I 46 (25.6\%) & $22(3.9 \%)$ & 0.71 \\
\hline $\mathrm{DM}(\%)$ & $155(27.2 \%)$ & $33(5.8 \%)$ & 0.3 & $159(27.9 \%)$ & $29(5.1 \%)$ & 0.54 \\
\hline CAD (\%) & 37 (6.5\%) & $6(1.1 \%)$ & 0.39 & $39(6.8 \%)$ & $4(0.7 \%)$ & 0.36 \\
\hline Cirrhosis (\%) & $3(0.5 \%)$ & $3(0.5 \%)$ & 0.04 & $3(0.5 \%)$ & $3(0.5 \%)$ & 0.01 \\
\hline ESRD (\%) & $9(1.6 \%)$ & $5(0.9 \%)$ & 0.1 & $10(1.8 \%)$ & $4(0.7 \%)$ & 0.1 \\
\hline \multicolumn{7}{|c|}{ Laboratory parameter } \\
\hline Hemoglobin $( \pm S D)$ & $10.5 \pm 2.6$ & $11.04 \pm 2.6$ & 0.005 & $10.8 \pm 2.6$ & $10.7 \pm 2.5$ & 0.57 \\
\hline Platelet count $( \pm$ SD) & $277 \pm 135$ & $281 \pm 116$ & 0.57 & $280 \pm|3|$ & $272 \pm 135$ & 0.78 \\
\hline Albumin $( \pm S D)$ & $2.87 \pm 1.05$ & $2.87 \pm 0.7$ & 0.96 & $2.87 \pm 1$ & $2.91 \pm 0.98$ & 0.7 \\
\hline INR $( \pm S D)$ & $|| \pm 0.3 \mid$. & $1.13 \pm 0.29$ & 0.4 & $1.11 \pm 0.29$ & $1.1 \pm 0.37$ & 0.84 \\
\hline
\end{tabular}

Abbreviations: CAD, coronary artery disease; CVA, cerebrovascular accident; DM, diabetes mellitus; ESRD, end-stage renal disease; INR, international normalized ratio; PEG, percutaneous endoscopic gastrostomy; SD, standard deviation. 
Table 3 Incidence of bleeding post-PEG tube placement with concomitant use of different index medications

\begin{tabular}{|c|c|c|c|c|c|c|}
\hline \multirow{3}{*}{$\begin{array}{l}\text { Index medication } \\
\text { SRIs }\end{array}$} & \multicolumn{6}{|c|}{ Bleeding interval } \\
\hline & \multicolumn{2}{|c|}{$<48$ hours after $\mathbf{P E G}$} & \multirow{2}{*}{$\begin{array}{l}P \text {-value } \\
0.595\end{array}$} & \multicolumn{2}{|c|}{ Between 48 hours and I 4 days } & \multirow{2}{*}{$\frac{P \text {-value }}{0.75 \text { I }}$} \\
\hline & $52(9.1 \%)$ & $14(2.5 \%)$ & & $56(9.8 \%)$ & $10(1.8 \%)$ & \\
\hline & No bleeding & Bleeding & & No bleeding & Bleeding & \\
\hline SSRIs & & & 0.177 & & & 0.805 \\
\hline Citalopram & $6(1.1 \%)$ & I $(0.2 \%)$ & & $7(1.2 \%)$ & $0(0 \%)$ & \\
\hline Escitalopram & $9(1.6 \%)$ & $4(0.7 \%)$ & & II (I.9\%) & $2(0.4 \%)$ & \\
\hline Fluoxetine & $10(1.8 \%)$ & $3(0.5 \%)$ & & $10(1.8 \%)$ & $3(0.5 \%)$ & \\
\hline \multicolumn{7}{|l|}{ Fluvoxamine } \\
\hline \multicolumn{7}{|l|}{ Paroxetine } \\
\hline Sertraline & $26(4.6 \%)$ & $5(0.9 \%)$ & & $28(4.9 \%)$ & $3(0.5 \%)$ & \\
\hline SNRIs & & & 0.67 & & & 0.72 \\
\hline Duloxetine & $0(0 \%)$ & I $(0.2 \%)$ & & I (0.2\%) & $0(0 \%)$ & \\
\hline Venlafaxine & $2(0.4 \%)$ & I (0.2\%) & & $2(0.4 \%)$ & I (0.2\%) & \\
\hline \multicolumn{7}{|l|}{ Antithrombotic } \\
\hline Aspirin & 175 (30.7\%) & 45 (7.9\%) & 0.42 & $187(32.8 \%)$ & $33(5.8 \%)$ & 0.54 \\
\hline Aspirin dose & & & 0.802 & & & \\
\hline Aspirin (8I mg) & I 58 (27.7\%) & $40(7 \%)$ & & & & \\
\hline Aspirin (325 mg) & $17(3 \%)$ & $5(0.9 \%)$ & & & & \\
\hline Plavix & $10(1.8 \%)$ & $6(1.1 \%)$ & 0.052 & 14 (2.5\%) & $2(0.4 \%)$ & 0.087 \\
\hline \multicolumn{7}{|c|}{ Therapeutic anti-coagulation } \\
\hline Heparin & 14 (2.5\%) & $9(1.6 \%)$ & 0.011 & $19(3.3 \%)$ & $4(0.7 \%)$ & 0.619 \\
\hline LMWH & $4(0.7 \%)$ & I (0.2\%) & 0.945 & $3(0.5 \%)$ & $2(0.4 \%)$ & 0.09 \\
\hline Coumadin & $10(1.8 \%)$ & $5(0.9 \%)$ & 0.144 & II (1.9\%) & $4(0.7 \%)$ & 0.147 \\
\hline \multicolumn{7}{|c|}{ Prophylactic anti-coagulation } \\
\hline Heparin & $248(43.5 \%)$ & $35(6.1 \%)$ & 0.011 & $204(35.8 \%)$ & 45 (7.9\%) & 0.011 \\
\hline \multicolumn{7}{|l|}{ Others } \\
\hline NSAIDs & $22(3.9 \%)$ & $4(0.7 \%)$ & 0.645 & $21(3.7 \%)$ & $5(0.9 \%)$ & 0.422 \\
\hline \multicolumn{7}{|c|}{ Synergistic effect with SRIs } \\
\hline $\mathrm{SRI}+$ aspirin & $24(4.2 \%)$ & $5(0.9 \%)$ & 0.825 & $25(4.4 \%)$ & $4(0.7 \%)$ & 0.988 \\
\hline SRI + NSAIDs & $5(0.9 \%)$ & $\mathrm{I}(0.2 \%)$ & 0.893 & $4(0.7 \%)$ & $2(0.4 \%)$ & 0.166 \\
\hline
\end{tabular}

Abbreviations: LMWH, low molecular weight heparin; NSAIDs, non-steroidal anti-inflammatory drugs; PEG, percutaneous endoscopic gastrostomy; SD, standard deviation; SNRIs, selective serotonin and norepinephrine reuptake inhibitors; SRIs, serotonin reuptake inhibitors; SSRIs, selective serotonin reuptake inhibitors.

in the hemoglobin of $\geq 2 \mathrm{~g} / \mathrm{dL} .{ }^{11}$ In our study, most of the PEG tube placements were done on patients while hospitalized. They were more likely to receive excess of intravenous fluids to compensate for the loss of enteral feeding.

Antiplatelet agents like aspirin pose increase the risk for post-surgical bleeding. ${ }^{12}$ However, in the absence of an underlying bleeding disorder, aspirin has not been shown to increase the risk of bleeding after PEG tube placement and hence can be continued. ${ }^{8,13}$ In our study, aspirin was not linked with increased risk of bleeding. The aspirin doses of $81 \mathrm{mg}$ and $325 \mathrm{mg}$ did not have any statistically significant difference in terms of post-PEG bleeding. The bleeding

Table 4 Incidence of presentations of gastrointestinal bleeding post-PEG tube placement in the presence of different index medications

\begin{tabular}{|c|c|c|c|c|}
\hline \multirow[t]{2}{*}{ Type of bleeding event } & \multicolumn{4}{|c|}{ Medication during the index PEG } \\
\hline & SRIs & Heparin & LMWH & Heparin SQ \\
\hline \multicolumn{5}{|l|}{ Difference in hemoglobin } \\
\hline$<48$ hours & $8(1.4 \%)$ & $2(0.4 \%)$ & I $(0.2 \%)$ & $44(7.7 \%)$ \\
\hline 48 hours to 14 days & $3 *(0.5 \%)$ & $5(0.9 \%)$ & $2(0.4 \%)$ & $36(6.3 \%)$ \\
\hline \multicolumn{5}{|c|}{ PEG site oozing requiring blood transfusion } \\
\hline$<48$ hours & $4(0.7 \%)$ & $6 *(1.1 \%)$ & $0(0 \%)$ & $23(4 \%)$ \\
\hline 48 hours to 14 days & I (0.2\%) & $5 *(0.9 \%)$ & $\mathrm{I}(0.2 \%)$ & $10(1.8 \%)$ \\
\hline \multicolumn{5}{|l|}{ Hematemesis or melena } \\
\hline$<48$ hours & $2(0.4 \%)$ & $3(0.5 \%)$ & $0(0 \%)$ & $7(1.2 \%)$ \\
\hline 48 hours to 14 days & $0(0 \%)$ & $0(0 \%)$ & $0(0 \%)$ & $\mathrm{I}(0.2 \%)$ \\
\hline
\end{tabular}

Note: $* P$-value $<0.005$.

Abbreviations: LMWH, low molecular weight heparin; PEG, percutaneous endoscopic gastrostomy; SQ, subcutaneous; SRIs, serotonin reuptake inhibitors. 
Table 5 Multivariate analysis of the risk of post-PEG bleeding

\begin{tabular}{ll}
\hline Parameters & P-value \\
\hline SRIs & 0.446 \\
Subcutaneous heparin & 0.035 \\
Aspirin & 0.576 \\
Platelet count & 0.736 \\
INR & 0.480 \\
Liver cirrhosis & 0.111 \\
\hline
\end{tabular}

Abbreviations: INR, international normalized ratio; PEG, percutaneous endoscopic gastrostomy; SRIs, serotonin reuptake inhibitors.

risk from clopidogrel and therapeutic anticoagulation when continued during high-risk procedures such as PEG, sphincterotomy, and polypectomy is substantial. It is hence recommended to postpone the procedure until discontinuation of clopidogrel is safe. ${ }^{9}$

The versatility of SRIs has made them the first-line therapy for a multitude of psychiatric disorders. ${ }^{9}$ Abrupt cessation of the SRIs for 1 week may lead to "The selective serotonin reuptake inhibitor discontinuation syndrome", ${ }^{14}$ which usually does not have any life-threatening outcomes ${ }^{15}$ and resolves upon re-instating the SRI. There has been data correlating SRIs with the gastrointestinal hemorrhage. ${ }^{16,17}$ There has been a study showing increased odds of bleeding (odds ratio: 4.1 ) with SRIs administered within 24 hours of an invasive procedure. ${ }^{8}$ In our study, all patients on SRIs received the medication 48 hours before and after PEG tube placement. However, we did not notice any correlation between SRI use and post-PEG bleeding. The analysis did not show correlation between SRIs use and decrease in hemoglobin by $\geq 2 \mathrm{~g} / \mathrm{dL}$ between 48 hours and 14 days; or other bleeding manifestations like oozing from the PEG site, hematemesis, and melena. There have been multiple reports in the literature about a synergistic effect of the combination of SRI with antithrombotic agents, on platelet function. ${ }^{18}$ However, in our study we did not notice any difference in the bleeding rates when SRIs were administered along with aspirin or NSAIDs. The other confounding factors could have nullified the post-PEG bleeding effect of the SRIs but multivariate analysis done for the same did not show any significantly increased risk of post-PEG bleeding in patients on SRIs even after controlling the use of unfractionated heparin in thrombophylactic dose, platelet count, INR, and liver cirrhosis. There is not enough literature to suggest that the interaction of either of the agents used for sedation (Midazolam or Propofol) with SRIs have a clinically significant effect on bleeding risk.

An increased risk of post-operative bleeding in the patients receiving thromboembolism prophylactic dose of the unfractionated heparin was observed in multiple studies done in the past, ${ }^{19,20}$ a finding that was replicated in our study. However, none of the bleeding events was life-threatening. There is no consensus yet to stop prophylactic dose of unfractionated heparin in patients undergoing PEG tube placement.

\section{Limitations}

The study was of retrospective design limited to one single inner city hospital. Although we had a sizeable study population of 570 patients, the study was most likely underpowered secondary to overestimation of prevalence of usage of SRIs. We also could not delineate if the patients had any other source of blood loss apart from gastrointestinal losses that might have contributed to the numbers in major blood loss group. We could not follow patients for a prolonged period of time post-discharge and therefore could not ascertain if more patients had major bleeding.

\section{Conclusion}

We did not notice an increase in post-PEG bleeding in patients on SRIs. However, in view of the limitation that our study is retrospective and that there are no known significant side effects of withdrawal of SRIs for a short duration, withholding SRIs could be a safe clinical option in patients undergoing PEG tube placement. Further studies, preferably prospective, are needed for better elucidation of SRI-induced risk of bleeding. Similarly, SQ heparin in thrombophylactic doses may cause non-life-threatening bleeding post-PEG but the safety and utility of alternative thrombophylactic strategies such as leg compression devices is yet to be verified.

\section{Disclosure}

The authors do not have a direct financial relation with the commercial identities mentioned in the paper that might lead to a conflict of interest, and report no conflicts of interest in this work.

\section{References}

1. Nielsen M, Gotzsche P. An analysis of psychotropic drug sales. Increasing sales of selective serotonin reuptake inhibitors are closely related to number of products. Int J Risk Saf Med. 2011;23(2):125-132.

2. Serebruany VL. Selective serotonin reuptake inhibitors and increased bleeding risk: are we missing something? Am J Med. 2006;119(2): 113-116.

3. Geiser F, Conrad R, Imbierowicz K, et al. Coagulation activation and fibrinolysis impairment are reduced in patients with anxiety and depression when medicated with serotonergic antidepressants. Psychiatry Clin Neurosci. 2011;65(5):518-525.

4. Bismuth-Evenzal Y, Gonopolsky Y, Gurwitz D, Iancu I, Weizman A, Rehavi M. Decreased serotonin content and reduced agonist-induced aggregation in platelets of patients chronically medicated with SSRI drugs. J Affect Disord. 2012;136(1-2):99-103. 
5. Reikvam AG, Hustad S, Reikvam H, Apelseth TO, Nepstad I, Hervig TA. The effects of selective serotonin reuptake inhibitors on platelet function in whole blood and platelet concentrates. Platelets. 2012;23(4): 299-308.

6. Szekely H, Tulassay Z. [Anticoagulation and antiplatelet therapy, and gastrointestinal endoscopy]. Orvosi Hetilap. 2009;150(12): 541-548.

7. Eisen GM, Baron TH, Dominitz JA, et al. Guideline on the management of anticoagulation and antiplatelet therapy for endoscopic procedures. Gastrointest Endosc. 2002;55(7):775-779.

8. Richter JA, Patrie JT, Richter RP, et al. Bleeding after percutaneous endoscopic gastrostomy is linked to serotonin reuptake inhibitors, no aspirin or clopidogrel. Gastrointest Endosc. 2011;74(1):22-34. e1.

9. ASGE Standards of Practice Committee, Anderson MA, Ben-Menachem T, et al. Management of antithrombotic agents for endoscopic procedures. Gastrointest Endosc. 2009;70(6):1060-1070.

10. Schapiro GD, Edmundowicz SA. Complications of percutaneous endoscopic gastrostomy. Gastrointest endosc Clin N Am. 1996;6(2): 409-422.

11. Gianserra CV, Aguero AP, Chapelet AG, Paradiso B, Spanevello VA, Del Pino MA. [Hospital-acquired anemia and decrease of hemoglobin levels in hospitalized patients]. Medicina. 2011;71(3):201-206.

12. Burger W, Chemnitius JM, Kneissl GD, Rucker G. Low-dose aspirin for secondary cardiovascular prevention - cardiovascular risks after its perioperative withdrawal versus bleeding risks with its continuation review and meta-analysis. J Intern Med. 2005;257(5):399-414.
13. Singh D, Laya AS, Vaidya OU, Ahmed SA, Bonham AJ, Clarkston WK. Risk of bleeding after percutaneous endoscopic gastrostomy (PEG). Dig Dis Sci. 2012;57(4):973-980.

14. Haddad P. The SSRI discontinuation syndrome. J Psychopharmacol. 1998;12(3):305-313.

15. Warner CH, Bobo W, Warner C, Reid S, Rachal J. Antidepressant discontinuation syndrome. Am Fam Phys. 2006;74(3):449-456.

16. Anglin R, Yuan Y, Moayyedi P, Tse F, Armstrong D, Leontiadis GI. Risk of upper gastrointestinal bleeding with selective serotonin reuptake inhibitors with or without concurrent nonsteroidal anti-inflammatory use: a systematic review and meta-analysis. Am J Gastroenterol. 2014; 109(6):811-819.

17. Targownik LE, Bolton JM, Metge CJ, Leung S, Sareen J. Selective serotonin reuptake inhibitors are associated with a modest increase in the risk of upper gastrointestinal bleeding. Am J Gastroenterol. 2009; 104(6):1475-1482.

18. Dalton SO, Sorensen HT, Johansen C. SSRIs and upper gastrointestinal bleeding: what is known and how should it influence prescribing? CNS Drugs. 2006;20(2):143-151.

19. Eppsteiner RW, Shin JJ, Johnson J, van Dam RM. Mechanical compression versus subcutaneous heparin therapy in postoperative and posttrauma patients: a systematic review and meta-analysis. World $J$ Surg. 2010;34(1):10-19.

20. White RH. Therapeutics. Review: heparin and mechanical compression are similar in reducing postsurgical VTE risk, but heparin increases bleeding. Ann Intern Med. 2010;153(2):JC1-JC7.
Therapeutics and Clinical Risk Management

\section{Publish your work in this journal}

Therapeutics and Clinical Risk Management is an international, peerreviewed journal of clinical therapeutics and risk management, focusing on concise rapid reporting of clinical studies in all therapeutic areas, outcomes, safety, and programs for the effective, safe, and sustained use of medicines. This journal is indexed on PubMed Central, CAS,

\section{Dovepress}

EMBase, Scopus and the Elsevier Bibliographic databases. The manuscript management system is completely online and includes a very quick and fair peer-review system, which is all easy to use. Visit http://www.dovepress.com/testimonials.php to read real quotes from published authors.

Submit your manuscript here: http://www.dovepress.com/therapeutics-and-clinical-risk-management-journal 